\title{
Online ore monitoring using EDXRF method on process conveyor belts at Kazakhmys Corporation LLC operations
}

\author{
Tetiana Oliinyk ${ }^{1}$, Sergey Yefimenko ${ }^{2}$, Zaure Abdrakhmanova ${ }^{2}$, Andrey $\mathrm{Kan}^{2}$, and Farida Issatayeva $^{3, *}$ \\ ${ }^{1}$ Kryvyi Rih National University, Ukraine \\ ${ }^{2}$ Kazakhmys Corporation LLC, Kazakhstan \\ ${ }^{3}$ Karaganda State Technical University, Kazakhstan
}

\begin{abstract}
The paper discusses organizing online ore monitoring on process conveyor belts at the operations of Kazakhmys Corporation LLC using EDXRF method implemented as an ore-controlling station (OCS) targeting ore size of $-300 \mathrm{~mm}$. OCS is supposed to achieve the objective of providing reliable silver detection measurements in the range of $1+$ ppm. Objects of monitoring: copper-containing polymetallic ores delivered to Zhezkazgan, Balkhash and Karagaily processing plants for treatment (target elements include copper, zinc, lead, silver, cadmium, and iron) as well as ores transported by the main underground feeder belt at Nurkazgan Mine (copper, zinc, lead, silver, molybdenum, and iron). The ultimate of the studies was to produce an online report on quality and quantities of ore and metals delivered from each of ore suppliers; to adjust the tonnages dispatched by the various shafts and open pits in the online mode; obtain reliable proof for unbiased redistribution of metals back to the mining operations. Equipment used during the studies: EDXRF OCS RLP21T. Key features of the unit are also discussed. The results of bench-scale testing as well as industrial application of OCS RLP-21T are discussed leading to the conclusion of successful online monitoring of silver in ores sized from $+1 \mathrm{ppm}$ to $-300 \mathrm{~mm}$. The photographs were provided by S. A. Yefimenko.
\end{abstract}

\section{Introduction}

Pertinent issues in minerals mining include integrated mineral resource mining, underground resource reproduction, and maximum recovery of useful components during ore processing. Integrity of mineral use will radically reduce intensive technogenic environmental impact of mining operations and improve the geological and environmental conditions in Ukraine's industrial regions. Substantiation of efficient recovery of rare, valuable and noble metals in such minerals is an urgent problem for iron ore processing in Kryvyi Rih iron ore basin.

For example, ferruginous quartzites of Kryvyi Rih iron ore basin contain $0.114-0.3 \mathrm{~g} / \mathrm{t}$ of gold. Gold occurs in the finely dispersed state in the form of elongated grains of (3-15) $\times 10^{-3} \mathrm{~mm}$ and plate aggregates with rounded edges in magnetite and in quartz.

Gold is found in low-grade magnetite ores of Kryvyi Rih iron ore basin and is unevenly distributed in different deposits. In the initial ore of Northern GOK, bound-state gold grades range from $0.016 \mathrm{~g} / \mathrm{t}$ to $0.03 \mathrm{~g} / \mathrm{t}$, which was confirmed through mercury amalgamation studies detecting no free gold. In the south of Kryvyi Rih iron ore basin, the ore mined from Novo-Krivorozhsky and Ingulets GOKs has a somewhat higher average gold grade of $0.034-0.067 \mathrm{~g} / \mathrm{t}$, reaching $0.11-0.347 \mathrm{~g} / \mathrm{t}$ in some areas.

Mineralogical studies have confirmed that free gold is contained only in ore sized less than $(8-10) \times 10^{-3} \mathrm{~mm}$, therefore less than $10 \%$ is disclosed. The remaining $90 \%$ of the total gold contained in the initial ore is dispersed in quartz and silicates, as well as in magnetite, carbonates and other minerals. Higher gold grades as compared with average background minerals is found in iron ore areas with a higher content of iron sulfides, pyrite and pyrrotite. The discovered free gold in the form of thin plates is foil gold.

Determination of the grades not only for gold but also for all valuable elements contained in iron ores will enable assessing their extraction prospects in the form of byproducts as early as at the stage of iron ore mining.

While conducting investigations into this matter, it is reasonable to study experience of Kazakhmys Corporation LLC.

Kazakhmys Corporation LLC is the largest copper producer in Kazakhstan that develops copper sandstones deposits of Zhezkazgan and Zhaman-Aybat $(\mathrm{Cu}, \mathrm{Pb}, \mathrm{Zn}$, $\mathrm{Ag}, \mathrm{Re}, \mathrm{Cd}, \mathrm{S}, \mathrm{Os}$ ), a gold-copper-porphyry deposit in Nurkazgan (Cu, Au, Ag, Mo, Se, S), pyrite-copper-leadzinc deposits of Kusmuryn and Akbastau $(\mathrm{Cu}, \mathrm{Zn}, \mathrm{Pb}, \mathrm{Au}$, $\mathrm{Ag}, \mathrm{Cd}, \mathrm{Se}, \mathrm{S}, \mathrm{Te})$, Shatyrkol porphyry-copper deposit $(\mathrm{Cu}, \mathrm{Mo}, \mathrm{Au}, \mathrm{Ag}, \mathrm{Te}, \mathrm{Se}, \mathrm{U})$, Abyz gold-pyrite-copperlead-zinc ore ( $\mathrm{Pb}, \mathrm{Zn}, \mathrm{Cu}, \mathrm{Au}, \mathrm{Ag}, \mathrm{S}, \mathrm{Se}, \mathrm{Te}, \mathrm{Cd}, \mathrm{In}, \mathrm{Hg}$ ), and Sayak group of copper-skarn deposits $(\mathrm{Cu}, \mathrm{Mo}, \mathrm{Fe}$, $\mathrm{Au}, \mathrm{Ag}, \mathrm{Bi}, \mathrm{Te}, \mathrm{Se}, \mathrm{Re})$.

Deposits are developed using underground and opencast mining methods at Zhezkazgan, Balkhash and Karaganda production sites. Copper grades in mined ores

\footnotetext{
* Corresponding author: adambekova farid@mail.ru
} 
have been decreasing steadily. Economic losses from the downward trend were offset by associated silver production.

Silver grades are low and therefore economic sustainability of mine production planning systems will heavily depend on possible online monitoring of copper and silver grades in exploration phase, in preparation and production mining as well as during ore delivery to processing plants. Based on the above, implementation of online monitoring of copper and silver grades would be addressing two independent objectives as follows:

- online monitoring of ores at the stage of exploration, mining and production;

- online monitoring of ores in transit to processing facilities. This study helps achieve this specific objective also addressing the issues associated with easing tensions arising between mining and ore processing facilities with regard to cyclone overflow metal redistribution.

This objective was being addressed within the framework of the Import Substitution Program administered by the Republic of Kazakhstan in the mining sector and as part of the range of projects aiming to retrofit and expand production at Kazakhmys Corporation LLC in 2017-2025.

Online monitoring of ores delivered to processing plants is highly challenging in technical terms due to the following factors:

- large ore size of $-300 \mathrm{~mm}$;

- often heavily slimed ore;

- low silver grades (from 1 to $25 \mathrm{ppm}$ );

- complex ores;

- ores come from different mining sources;

- at one of the facilities (Balkhash Processing Plant) ores are treated in a blend with Balkhash Copper Smelter slags characterized by highly complex grades matrix.

The above-listed factors clearly indicate that such a difficult objective has never been addressed successfully before regardless of the methods applied.

This study focused on ores brought to processing plants on conveyor belts as well as the material carried by underground conveyor belt at Nurkazgan Mine.

\section{Method and geophysical apparatus}

This study pursues the goal of establishing a unified, reliable and highly efficient online monitoring system of tracking the ever changing chemical composition of copper-bearing polymetallic ores at mining and processing operations of Kazakhmys Corporation LLC, which would focus on the key target element (copper) and equally on the accompanying (silver, cadmium, molybdenum) target elements.

To date, non-ferrous metallurgy has seen no examples of an efficient solution for online monitoring of ores with a particle size of $-300 \mathrm{~mm}$ and silver and cadmium grades of $1+$ ppm by any physical methods on process conveyor belts using suspended ore controlling stations (OCS).

The global OCS market is diverse and offers - energy dispersive X-ray fluorescence (EDXRF) systems such as OCS STARK (KrasnRados LLC, Krasnoyarsk), OCS-KM (Technoros LLC, Krasnoyarsk), Online
Conveyor XRF Analyzer Con X-03 (Baltic Scientific Instruments Ltd, Latvia), OCS ARP-1Ts (Tekhanalitpribor LLC, Moscow);

- Gamma Neutron Activation Assay (PGNAA) OCS such as CB Omni (Thermo Fisher Scientific, Australia), GEOSCAN (Scantech. Australia), NITA II (ScanMin Africa, South Africa), EBA 1-2 CE (ENCE GmbH, Switzerland ); OCS based on NIR (near infrared) spectroscopy SpectraFlow Crossbelt (SpectraFlow Analytics Switzerland, Switzerland); OCS based on laserinduced breakdown spectroscopy (LIBS) MAYA-6060 (Laser Detect System - LDS, Israel) [1-5].

Only the EDXRF RCS can be best accommodated within the dimensions of the conveyor galleries at Kazakhmys Corporation LLC processing plants. Positive experience has been demonstrated using EDXRF OCS RLP-3-02 (Geotech LLC, Saint-Petersburg, Russia) at Zhezkazgan concentration plants (ZPP-1 and ZPP-2) since 2014 [6, 7]. During the production operation it was discovered that the OCS-RLP-02 was not capable of clear determination of low silver grades, which cast it out of the ranks of equipment to be included in the program.

The import substitution program dictated that EDXRF OCS RLP-21T (Aspap Geo LLC, Almaty, Kazakhstan) should be chosen as the base unit for the study. OCS RLP$21 \mathrm{~T}$ was designed specifically to determine low $(2+\mathrm{ppm})$ silver grades (Fig. 1). The most advanced X-ray tubes, silicon drift detectors, the latest high-speed electronics and powerful software are used in the OCS, which ensured confident determination of silver and cadmium grades of $2+\mathrm{ppm}$. This conclusion was made according to the results of bench tests on control powder and finely ground samples at ZPP-1 and ZPP-2.

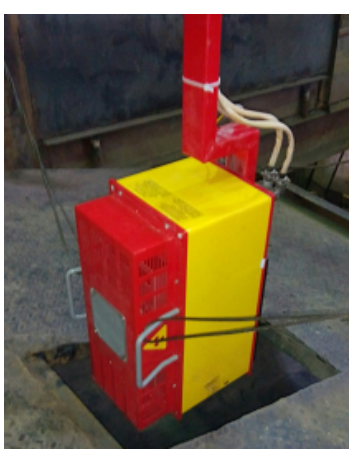

Fig. 1. OCS RLP-21T.

At ZPP-1 and ZPP-2, ore is received from Zhezkazgan and Zhaman-Aibat deposits boasting higher silver grades compared to ores from other deposits (average grades of 15 ppm).

A much more complicated case is the Balkhash Processing Plant (BPP), which receives ores from Nurkazgan, Sayak Group, Kounrad, Shatyrkol, and Akzhal deposits and also treats waste slags from the Balkhash Copper Smelter (BCS) characterized by a highly complex elemental matrixes for interpretation by $\mathrm{X}$-ray fluorescence method, e.g.: $\mathrm{Cu}=1.15 \%, \mathrm{Zn}=5.90 \%$, $\mathrm{Pb}=0.65 \%, \mathrm{Fe}=46.80 \%$. Ores treated at BPP have very low silver grades (usually less than $10 \mathrm{ppm}$, while Kounrad and Nurkazgan have less than $3 \mathrm{ppm}$ ) and a broad range of copper grades (0.2-4\%). 
Karagaily Processing Plant (KPP) treats ores from Akbastau and Abyz deposits. Nurkazgan processing Plant (NPP) only treats ore from Nurkazgan UG mine (NUGM).

A large number of OCS installation locations and several deposits within the scope of this study dictated the need to solve the problem in two stages. At the first stage of research, OCS-RLP-21T was tested on ore from deposits that are processed at ZPP-1 and ZPP-2. This stage helped identify the true scope of OCS RLP-21T capabilities in terms of sustainable performance on low silver and cadmium grades and recommendations were made on improving the hardware, methodology and software for the OCS RLP-21T to guarantee positive performance of the unit in the second stage (BPP, KPP, NIR).

\section{Study results}

After completion of the full cycle of bench and industrial tests of the OCS-RLP-21T on conveyors, in October 2016 it was launched on conveyor No. 1T ZhDM-2 (Fig. 2, left), and in January 2017 similar units were installed on conveyors No. 2T ZPP-2 (Fig. 3, right), and No. 1A ZPP1 (Fig. 4, right) [6-7].

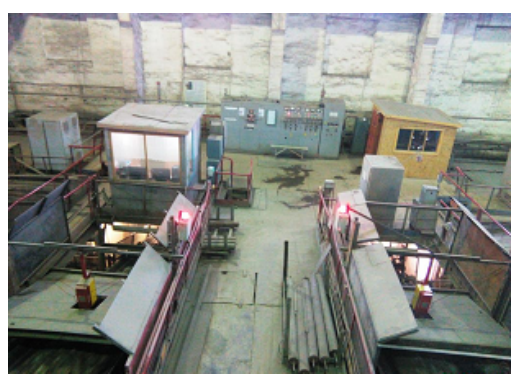

Fig. 2. OCS RLP-21T on conveyors No. $1 \mathrm{~T}$ and No. $2 \mathrm{~T}$ ZhDM-2.

The optimal measurement procedure was selected. Single measurements $(1 \mathrm{sec})$ are performed one after another without gaps. grades of copper, zinc, lead and iron were calculated as averages of 20 single measurements; grades of silver, cadmium and molybdenum were the averages of every 40 single measurements.

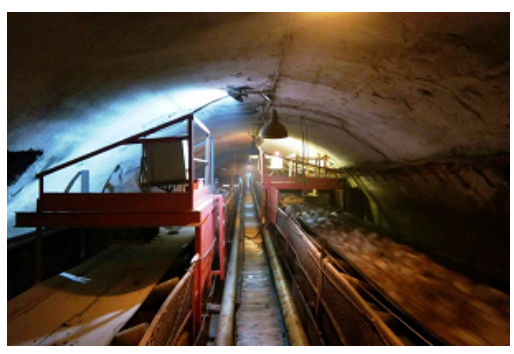

Fig. 3. OCS RLP-21T on conveyors No. 1A (right) ZhDM-1.

In the course of control sample studies, the influence of the height of OCS suspension on copper and silver grade determination accuracy was evaluated. It was found (within an exposure of $300 \mathrm{sec}$ ) that when changing the height of the RCC suspension from 22 to $72 \mathrm{~cm}$, the determined copper and silver grades did not change much: copper was from 0.776 to $0.785 \%$, and silver was from 10.95 to $9.8 \mathrm{ppm}$, but the measurement errors changed to a much greater extent: error for copper changed from \pm 0.0088 to $\pm 0.038 \%$, and error for silver changed from \pm 3.2 to $\pm 18.0 \mathrm{ppm}$.

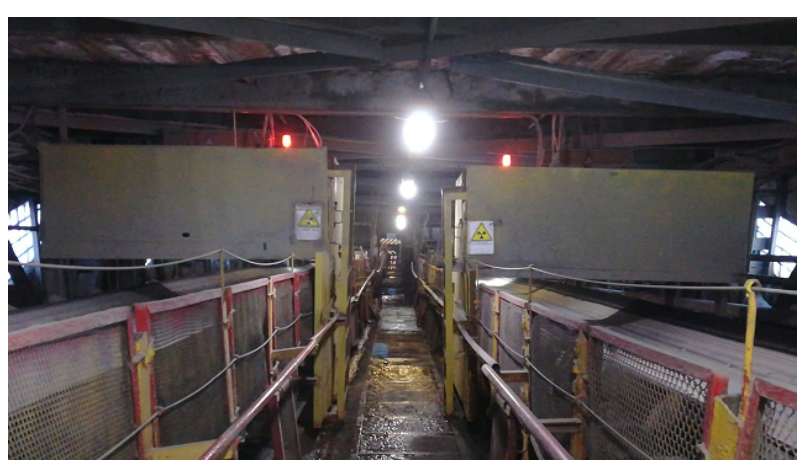

Fig. 4. OCS RLP-21T on conveyors No. 2 and No. 2A BPP.

Accounting for the variable ore-OCS gap in the RLP21T OCS is carried out in two ways: by the MaxBotix MB7067 ultrasonic distance sensor; by the intensity of the scattered radiation of the elements composing the ore on the conveyor belt. MaxBotix MB7067 is the primary way to track the variable ore-PKC clearance. The results of the production operation of the two OCS RLP-21T units in 2019 at ZPP-1 are shown in table 1.

Table 1. The results of the OCS RLP-21T on the conveyor No. 1A ZPP-1 for 2019.

\begin{tabular}{|c|c|c|c|c|c|c|}
\hline \multirow{2}{*}{\begin{tabular}{|c|}
2019 \\
month
\end{tabular}} & \multicolumn{3}{|c|}{ Copper, \% } & \multicolumn{3}{|c|}{ Silver, ppm } \\
\hline & Overlfow & OCS & $\sigma, \%$ & Overflow & OCS & $\sigma, \%$ \\
\hline 1 & 0,91 & \begin{tabular}{|l|}
0,88 \\
\end{tabular} & 3,30 & 13,351 & 13,07 & 2,10 \\
\hline 2 & 0,88 & \begin{tabular}{|l|}
0,87 \\
\end{tabular} & 1,14 & 10,821 & 10,792 & 0,27 \\
\hline 3 & 0,97 & 0,91 & 6,19 & 10,183 & 9,891 & 2,87 \\
\hline 4 & 0,97 & \begin{tabular}{|l|}
0,93 \\
\end{tabular} & 4,12 & 9,860 & 9,383 & 4,84 \\
\hline 5 & 0,964 & 0,926 & 3,94 & 191 & 8,83 & 3,93 \\
\hline 6 & 978 & 0,983 & 0,51 & 10,263 & 9,75 & 4,97 \\
\hline 7 & 1,071 & 1,089 & 1,68 & 9,70 & 9,426 & 2,82 \\
\hline 8 & 1,026 & 1,080 & 5,26 & 8,328 & 8,755 & 5,13 \\
\hline 9 & 1,059 & 1,057 & 0,19 & 8,734 & 8,752 & 0,21 \\
\hline 10 & 1,024 & 1,040 & 1,56 & 274 & 8,888 & 7,42 \\
\hline 11 & 1,042 & 1,056 & 1,34 & 536 & 8,512 & 0,28 \\
\hline 12 & 1,094 & 1,076 & 65 & 8,666 & 8,441 & 2,60 \\
\hline 2019 & 0,999 & 0,991 & 0,76 & 9,659 & 9,541 & 1,22 \\
\hline
\end{tabular}

The results of the production operation of the OCS RLP-21T in 2019 at ZPP-2 are shown in table 2.

The first stage of research on the introduction of the RLP-21T OCS was completed successfully and it was decided to move on to the second stage of tests.

All four new OCS RLP-21T units designed for more complex analytical tasks at the BPP and NIR in were equipped the following components: more powerful X-ray tubes with a working voltage of $60 \mathrm{kV}$; silicon drift detectors (SDD) of a larger area; state-of-the-art highspeed electronics; upgraded software package for new challenging analytical tasks. Two RLP-21T OCS units intended for testing at BPP had to be deprived of the unified calibration of the RLP-21T spectrometer and were switched to include on-object calibration. The desired calibration is selected automatically depending on the 
grades of the main elements (as well as iron) and entries in weighing tickets. The remaining two OCS RLP-21T units retained the measurement procedure underpinned by the basic principle of Aspap Geo LLC: x-rayed objects are different in varying ore types with a range of ore processing products - delivered - all using the same calibration.

Table 2. The results of OCS RLP-21T on conveyors No. 1T and No. 2T at ZPP-2 in 2019.

\begin{tabular}{|c|c|c|c|c|c|c|}
\hline \multirow{2}{*}{$\begin{array}{c}2019 \\
\text { month }\end{array}$} & \multicolumn{3}{|c|}{ Copper, \% } & \multicolumn{3}{c|}{ Silver, ppm } \\
\cline { 2 - 7 } & Overflow & OCS & $\boldsymbol{\sigma}, \mathbf{\%}$ & Overflow & OCS & $\boldsymbol{\sigma ,} \%$ \\
\hline 1 & 0,86 & 0,82 & 4,65 & 11,546 & 11,848 & 2,62 \\
\hline 2 & 0,83 & 0,82 & 1,20 & 10,850 & 11,396 & 5,03 \\
\hline 3 & 0,81 & 0,80 & 1,23 & 10,732 & 11,393 & 6,16 \\
\hline 4 & 0,83 & 0,81 & 2,41 & 12,037 & 12,257 & 1,83 \\
\hline 5 & 0,777 & 0,74 & 4,76 & 11,226 & 11,545 & 2,84 \\
\hline 6 & 0,835 & 0,823 & 1,44 & 12,95 & 13,37 & 3,27 \\
\hline 7 & 0,821 & 0,825 & 0,49 & 13,73 & 13,923 & 1,41 \\
\hline 8 & 0,807 & 0,83 & 2,85 & 12,042 & 12,777 & 6,10 \\
\hline 9 & 0,820 & 0,812 & 0,98 & 13,037 & 13,363 & 2,50 \\
\hline 10 & 0,824 & 0,813 & 1,33 & 14,387 & 14,952 & 3,93 \\
\hline 11 & 0,799 & 0,810 & 1,38 & 14,057 & 14,779 & 5,14 \\
\hline 12 & 0,831 & 0,840 & 1,08 & 14,332 & 14,916 & 4,07 \\
\hline $\mathbf{2 0 1 9}$ & $\mathbf{0 , 8 2 0}$ & $\mathbf{0 , 8 1 2}$ & $\mathbf{1 , 0 3}$ & $\mathbf{1 2 , 5 7 7}$ & $\mathbf{1 3 , 0 4 4}$ & $\mathbf{3 , 7 1}$ \\
\hline
\end{tabular}

Since zinc is contained in the conveyor belt components, the time intervals on an idle or moving empty belt (as per belt motion sensor readings) were excluded from the data sets.

Before installation on conveyors, all OCS RLP-21T units passed the standard set of bench tests. In this case, sets of calibration samples of ores from each deposit with known chemical compositions for all six elements were used. Each set included three types of samples: powders, roller-crushed ore, and jaw-crushed materials. After each OCS was suspended directly over the respective conveyors, the entire cycle of testing on the samples was repeated respecting the limitation of conveyor idle time availability for testing.

The results of the second stage of studies were as follows:

1. At the BPP OCS RLP-21T installed on the input belt conveyors No. 2 and No. 2A and commissioned on May 4, 2018 (Fig. 4). Detected elements were copper, lead, zinc, silver, cadmium, and iron.

Since July 2018, the railcar test station of the technical control department (TCD) on the KKD 1500/180 cone crusher was decommissioned [8-9].

The results of the production operation of the OCS RLP-21T in 2019 at BPP are shown in table 3.

Over the entire period of OCS operation the following silver grades were recorded in one railway train: maximum - 11.5 ppm (Tastau mine) and 12.3 ppm (waste slag); minimum - 1.9 ppm (Kounrad mine). This is much lower than the level of silver in ores entering ZPP -1 and ZPP - 2. Thus, for the first time in global practice, EDXRF OCS was able to acurately detect such low silver grades in ores with a grain size of $-300 \mathrm{~mm}$.

2. At KPP the OCS RLP-21T unit was installed on conveyor belt No. 4 and commissioned on July 27, 2018
(Fig. 5). The ore size is $-50 \mathrm{~mm}$. Target elements are copper, lead, zinc, silver, cadmium, iron [8-9].

Table 3. The results of the OCS RLP-21T on conveyors No. 2 and No. 2A BPP in 2019.

\begin{tabular}{|c|c|c|c|c|c|c|}
\hline \multirow{2}{*}{$\begin{array}{c}2019 \\
\text { month }\end{array}$} & \multicolumn{3}{|c|}{ Copper, \% } & \multicolumn{3}{c|}{ Silver, ppm } \\
\cline { 2 - 7 } & Overflow & OCS & $\boldsymbol{\sigma}, \mathbf{\%}$ & Overflow & OCS & $\boldsymbol{\sigma , ~ \% ~}$ \\
\hline 1 & 1,11 & 1,13 & 1,80 & 4,94 & 4,32 & 12,55 \\
\hline 2 & 1,04 & 1,02 & 1,92 & 4,69 & 4,12 & 12,15 \\
\hline 3 & 0,92 & 0,94 & 2,17 & 3,26 & 3,66 & 12,3 \\
\hline 4 & 0,82 & 0,8 & 2,44 & 3,15 & 3,56 & 13,0 \\
\hline 5 & 0,94 & 0,98 & 4,26 & 3,42 & 3,84 & 12,3 \\
\hline 6 & 0,99 & 1,07 & 8,08 & 6,06 & 4,94 & 18,48 \\
\hline 7 & 0,98 & 1,07 & 9,18 & 6,33 & 4,19 & 33,81 \\
\hline 8 & 0,97 & 1,10 & 13,4 & 5,43 & 4,31 & 20,71 \\
\hline 9 & 0,84 & 0,89 & 5,95 & 5,47 & 3,99 & 27,11 \\
\hline 10 & 0,89 & 0,97 & 8,99 & 5,56 & 4,07 & 26,80 \\
\hline 11 & 0,89 & 0,93 & 4,49 & 5,14 & 3,99 & 22,37 \\
\hline 12 & 1,00 & 1,02 & 2,00 & 5,22 & 4,66 & 10,73 \\
\hline $\mathbf{2 0 1 9}$ & $\mathbf{0 , 9 4 9}$ & $\mathbf{0 , 9 9 3}$ & $\mathbf{4 , 6 5}$ & $\mathbf{4 , 8 8 9}$ & $\mathbf{4 , 1 3 7}$ & $\mathbf{1 5 , 3 9}$ \\
\hline
\end{tabular}

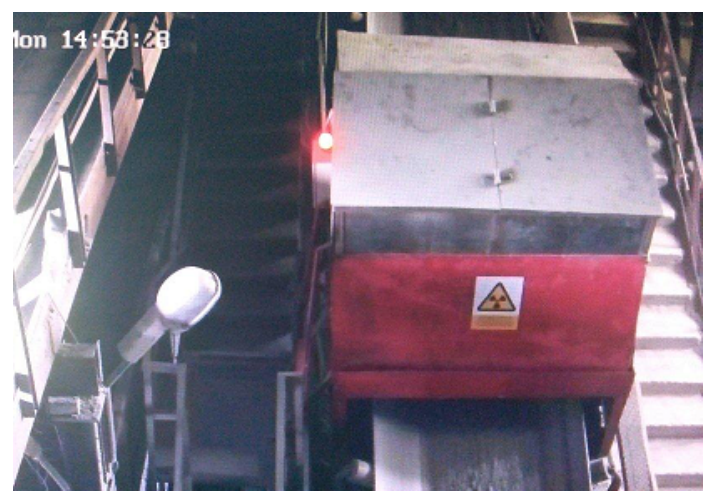

Fig. 5. OCS RLP-21T on conveyor No. 4 KPP.

The following silver contents were recorded in one five-minute measurement: $19.6 \mathrm{ppm}$ (maximum) and 6.5 ppm (minimum). This is another confirmation of efficiency shown by unique methodological and mathematical fragments of the OCS RLP-21T.

3. OCS RLP-21T unit on the main conveyor belt of the Nurkazgan underground mine was put into operation on June 14, 2018 (Fig. 6). Target elements are copper, lead, zinc, silver, cadmium, and iron.

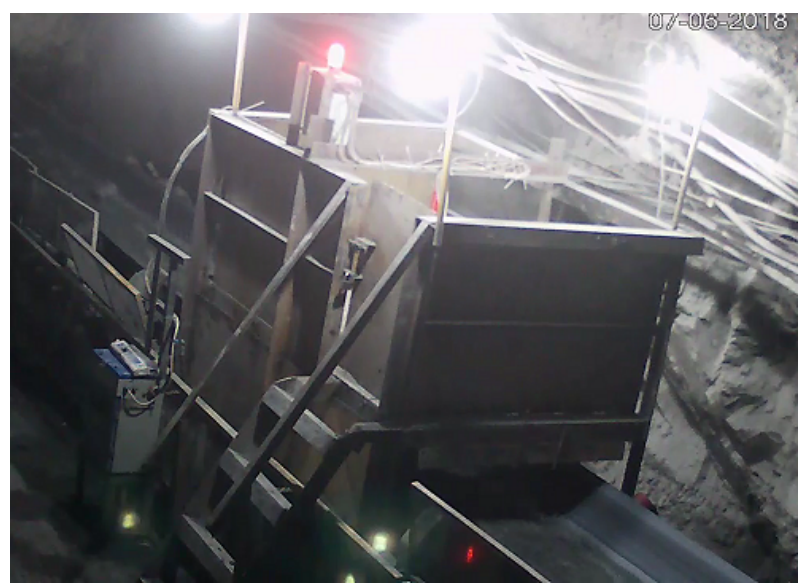

Fig. 6. OCS RLP-21T on the main conveyor of the NPR. 
The following silver and molybdenum grades were recorded in one five-minute interval: silver $-7.4 \mathrm{ppm}$ (maximum) and $1.1 \mathrm{ppm}$ (minimum); molybdenum $0.1370 \%$ (maximum) and $0.0011 \%$ (minimum) [8-9].

4. In August 2019, the most recent modification of OCS-RLP-21T (the same as at BPP, KPP and NIR) was installed on conveyor No. 1 ZPP-1 (Fig. 2, left) to replace the OCS RLP-3-02 (Fig. 7). For ease of maintenance, this OCS folds the floor at an angle of $90^{\circ}$ [9].

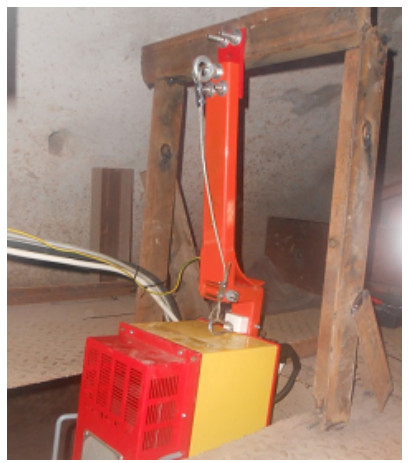

Fig. 7. OCS RLP-3-02 on conveyor No. 1 at ZPP-1.

The difference between conveyor No. 1 and conveyor No. $1 \mathrm{~A}$ is that ore flow on conveyor No. 1 is noticeably more narrow than on conveyor No. 1A. Zinc is present in the material of the conveyor belt, so measures had to be taken to reduce the "viewing range" of the OCS RLP-21T. Sensitivity of the EDXRF method decreased and the decrease was compensated through applying $60 \mathrm{kV}$ instead of $50 \mathrm{kV}$ to the X-ray tube.

The results of production operation of the OCS RLP$21 \mathrm{~T}$ in 2019 on conveyor No. 1 at ZPP-1 are shown in Table 4.

Table 4. The results of the OCS RLP-21T on the conveyor No. 1 ZhOF-1 for 2019.

\begin{tabular}{|c|c|c|c|c|c|c|}
\hline \multirow{2}{*}{$\begin{array}{c}2019 \\
\text { month }\end{array}$} & \multicolumn{3}{|c|}{ Copper, \% } & \multicolumn{3}{c|}{ Silver, ppm } \\
\cline { 2 - 7 } & Overflow & OCS & $\boldsymbol{\sigma , ~ \%}$ & Overflow & OCS & $\boldsymbol{\sigma , ~ \%}$ \\
\hline 8 & 0,638 & 0,728 & 14,11 & 8,700 & 7,394 & 15,01 \\
\hline 9 & 0,756 & 0,800 & 5,82 & 11,097 & 9,352 & 15,72 \\
\hline 10 & 0,716 & 0,767 & 7,12 & 10,252 & 9,85 & 3,92 \\
\hline 11 & 0,746 & 0,774 & 3,75 & 10,824 & 9,943 & 8,14 \\
\hline 12 & 0,776 & 0,803 & 3,48 & 11,131 & 11,592 & 4,14 \\
\hline $\mathbf{2 0 1 9}$ & $\mathbf{0 , 7 2 6}$ & $\mathbf{0 , 7 7 4}$ & $\mathbf{6 , 6 1}$ & $\mathbf{1 0 , 4 0 1}$ & $\mathbf{9 , 6 2 6}$ & $\mathbf{7 , 4 5}$ \\
\hline
\end{tabular}

The results of the RKS RLP-21T testing on conveyor No. 1 at ZPP-1 are not so successful compared to those from conveyors No. 1A at ZPP-1 or on conveyors No. 1T and No. 2T at ZPP-2. Based on 2019 performance, the calibration of the OCS RLP-21T will be slightly adjusted.

\section{Conclusions}

1. The unit for online grades monitoring of main (copper, lead, zinc) and related (silver, cadmium, molybdenum) elements in copper-containing polymetallic ores delivered to ZPP-1, ZPP-2, BPP, and KPP was developed, comprehensively tested and commissioned on production scale, and at ore mining facilities. The unit is based on
EDXRF OCS RLP-21T manufactured in Kazakhstan. The total of 8 OCS RLP-21T were commissioned.

2. For the first time in Kazakhstan's non-ferrous industry a reliable online system for monitoring coarse $-300 \mathrm{~mm}$ very low silver, cadmium $(1+\mathrm{ppm})$ and molybdenum $(10+$ ppm) grade ores was implemented on process conveyor belts on the scale of a very large mining company (Kazakhmys Corporation LLC). Real prerequisites have been established for the operational management of associated mining of these metals [14].

3. The problem was solved with minimal investments (a number of companies from Australia and South Africa had proposed to achieve this with the help of CSs using the gamma-neutron activation analysis method - PGNAA; the cost of one such OCS exceeded the cost of the eight currently deployed EDXRF CSL RLP-21T units).

4. With the introduction of the OCS, the miners are provided with online information on the quantities of metals and metal grades of the ore delivered to the processing plant during the shift, day and month-to-date, and are now able to promptly make the necessary adjustments to the process of ore and metal mining. The reliable evidence base is available for them to stand their ground in terms of the qualities of ore delivered to the processing plant during redistribution of overflow metal treated through the processing plant in a calendar month. 5. As a result of OCS installation on process conveyors at ore processing plants, the standard quality control testing points on cone crushers were decommissioned: KKD 800/160 (ZPP-1), KKD 1500/1800 (ZPP-2), KKD $1500 / 180$ (BPP) at ZPP-2.

6. Further practical application of the OCS RLP-21T is on conveyors carrying dried copper concentrate to Zhezkazgan Copper Smelter of Kazakhmys Smelting LLC (OCS CON-X from Baltic Scientific Instruments, Latvia is covering the scope at Balkhash Copper Smelter of Kazakhmys Smelting LLC).

7. OCS RLP-21T is used outside of Kazakhstan since 2019 when two OCS RLP-21T units were commissioned at CJSC Silver Magadan (Russia).

\section{References}

1. G.I. Rudko, F.M. Isataeva, V.S. Portnov, Geological and economic assessment of mineral reserves of Kazakhstan: an international aspect, Kazakhstan Industry 3, 104 (2018)

2. ABB, Online Analyzer SpectraFlow, ABB Schweiz, Baden-Dättwil (2013)

3. D. Karanin, A. Nogarev, A. Shishkin, Ore quality control system at a mining and processing plant. Standards and Quality 1 (2010)

4. E.N. Ishmetyev, A.V. Romanenko, A.I. Usherov, Z.G. Salikhov, A.V. Lednov, Production and analytical complex for continuous measurement of the chemical composition of materials in a stream in a metallurgical and mining industry. Information and control systems in industry $\mathbf{1}$ (2012)

5. B.T. Zhumagulov, A.K. Tuleshov, Yu.M. Drakunov, Computer modeling and control system for X-ray 
radiometrical well-logging unit, in World Congress on Engineering (London, 2010)

6. S.A. Yefimenko, O.S. Yefimenko, V.S. Portnov, A.D. Mausymbaeva, On-line nuclear-geophysical technologies for controlling the quality of ores supplied to the Zhezkazgan concentration plant, in 8 th scientific readings in memory of Yu.P. Bulashevich, Institute of geophysics, UB RAS, Ekaterinburg, 14-18 September 2015, vol. 1

7. Thermo Scientific, CBX-M Online PGNAA Elemental Analyser (2007)

8. Sodern, Neutron Elemental Analysis (2011), http://www.sodern.com/sites/en/ref/Neutronelemental-analysis_33.html. Accessed 25 Mar 2020

9. N. Battalgazy, N. Madani, Categorization of Mineral Resources Based on Different Geostatistical Simulation Algorithms: A Case Study from an Iron Ore Deposit. Natural Resources Research 28(4), 1329-1351 (2019). doi:10.1007/s11053-019-094749 